\title{
Creating Awareness about Adolescent Reproductive Health among Upper Primary School Students in Haryana through the Use of Interactive e-Modules
}

\author{
Deepti Chopra', Shalini Yadava ${ }^{2}$
}

${ }^{1}$ Research Scholar, ${ }^{2}$ Assistant Professor, University School of Education, Guru Gobind Singh Indraprastha University, Delhi, India. DOI: https://doi.org/10.24321/2349.2880.202019

I $\mathbf{N}$ F O

\section{Corresponding Author:}

Deepti Chopra, University School of Education, Guru Gobind Singh Indraprastha University, Delhi, India.

E-mail Id:

deeptichopra11@gmail.com

Orcid Id:

https://orcid.org/0000-0001-9782-5161

How to cite this article:

Chopra D, Yadava S. Creating Awareness about Adolescent Reproductive Health among Upper Primary School Students in Haryana through the Use of Interactive e-Modules. Ind J Youth Adol Health 2020; 7(4): 24-29.

Date of Submission: 2021-02-08

Date of Acceptance: 2021-03-25

\author{
$\begin{array}{llllllllllllll}\mathbf{A} & \mathbf{B} & \mathbf{S} & \mathbf{T} & \mathbf{R} & \mathbf{A} & \mathbf{C} & \mathbf{T}\end{array}$
}

Adolescents are the prospective citizens of any nation; therefore, investment in terms of the well-being of adolescents is considered quite rewarding. Adolescents are now attaining biological maturity earlier than the previous generation, as witnessed by the gradual decline in average age of puberty and menarche; hence, it becomes imperative to address this cohort of the population. Integration of technology in the field of education has been an area of research for a long. The present study attempts to use digital technology in the form of e-modules created through H5P in creating awareness about adolescent reproductive health on upper primary school students. A sample of 309 students from randomly selected ten unaided private schools of Sonipat district of Haryana was taken. Interactive e-modules were developed for addressing adolescent reproductive health. After the pre-test administration, the experimental group was taught through e-modules and the control group was taught through the conventional method. The data was collected through validated tools over a period of three months. A post-test was conducted afterward to assess the awareness level. After ascertaining comparability of the two groups, data was analyzed using percentage and t-statistics. The data analysis showed that the difference in the mean and standard deviation of the post-test scores of the experimental group $20.50 \pm 3.40$ and the control group $15.72 \pm 4.03$ were statistically significant at 0.001 level (t value $=11.26$, d.f. $=297$ ). Thus, the study concludes that the interactive e-modules effectively create awareness about adolescent reproductive health at the upper primary school stage.

Keywords: Adolescent Reproductive Health, Awareness, Intervention, e-modules, H5P, Digital Technology, Upper Primary School Stage 


\section{Introduction}

Technology has crept and blended into our lives to a great extent. We have glided past the era of alarm clocks, telephone directories, calculators, dictionaries, and many more articles which were once proudly owned and used by each one of us. How could then modern-day teachinglearning be left untouched by technological advancements? The present generation, often addressed as 'digital natives' ${ }^{1}$, tend to be much at ease using digital devices compared to the children and adults. ${ }^{2}$ Digital media and internet technologies offer an enormous possibility for reaching out to adolescents. ${ }^{3}$

The integration of technology as an effective tool for classroom teaching-learning for elementary classes has been well researched with positive outcomes of technology use in pedagogy. ${ }^{4-7} \mathrm{~A}$ review of studies to assess the KAP of adolescents across India has pointed out the gaps among adolescents regarding reproductive health. ${ }^{8-11} \mathrm{~A}$ review on "knowledge and understanding of menarche, menstrual hygiene, and menstrual health among adolescent girls in Low and Middle-Income Countries (LMIC)" reported that girls were unprepared for menarche as they are not equipped with adequate and timely information. The review further states that in India, older adolescents had better possession of knowledge than young adolescents. ${ }^{12}$ This lack of knowledge among adolescents regarding reproductive health is neither addressed by the school nor parents. Taking advantage of their ignorance, adolescents are often sexually abused ${ }^{13,14}$ and do not even know how to resist or report. Adolescents are now attaining biological maturity earlier than the previous generation, as witnessed by a gradual decline in the average age of puberty and menarche..$^{15}$ Hence, it becomes imperative to educate very young adolescents in the age bracket of 10-14 years regarding reproductive health. Reports state that the very young adolescents (10-14 years old) are mostly neglected as policymakers focus on older adolescents. ${ }^{16}$ Also, there is a paucity of data regarding them as none of the surveys seeks information from this cohort of adolescent population therefore; there is very little understanding of their needs. ${ }^{17}$

Eminent scholars from diverse fields like education, medicine, psychology, social work, and technology have reported different ways and means to address reproductive health. Also, the integration of digital technology to address the reproductive health of adolescents has been studied in varied contexts. Barak and Fischer studied the usage of two websites containing information on sexual and reproductive health for adolescents. Their study reported many users and multiple downloads within months of their launch and concluded the websites were helpful for adolescents to seek information. ${ }^{18}$ Cousineau TM et al. reported that their interactive computer-based program on puberty, 'Body
Morph,' could enhance knowledge and awareness about puberty among adolescents. ${ }^{19}$ Roberto AJ et al. reported that the computer and internet-based interventions increased knowledge and delay sexual initiation among rural adolescents. ${ }^{20}$ Bailey et al., in their systematic review of literature on the effectiveness of Interactive ComputerBased Interventions for sexual health promotion, reported these to be more effective than face-to-face interventions. ${ }^{21}$ Sancheti PV et al. investigated the effect of an audiovisual intervention on improving knowledge about reproductive health among adolescents and reported a significant increase in knowledge post intervention. ${ }^{22}$ Brayboy LM et al. studied the utility of a mobile app 'Girl Talk' and reported a substantial increase in knowledge of girls regarding many dimensions of reproductive and sexual health..$^{23}$ Calabrese investigated the effectiveness of mixed media methods for instructing six graders on sexual and reproductive health and reported increased knowledge retention of students. ${ }^{24}$ The literature review indicates a paucity of research in interactive digital interventions, especially for addressing reproductive health to very young adolescents in the Indian context. In order to reach out to these 'digital natives' with age-appropriate knowledge about reproductive health, this paper explores the effectiveness of e-modules in creating awareness about Adolescent Reproductive Health among Upper Primary School students.

\section{Materials and Methods \\ Phase I (Developmental Phase)}

The first phase of the study comprised of analysis of the science text books of classes VI to VIII, from Central Board of Secondary Education in lieu of adolescence, reproductive health and other related issues. The existing electronic resources were then reviewed to check for the e-content available to address adolescent reproductive health for the age group of 10-14 years. The review concluded that content and quality of the electronic resources available did not match the requirement of the very young adolescents (10-14 years old), especially in the cultural context of Haryana. The e-modules were then designed and developed to address the topic of Adolescent Reproductive Health to students of Upper Primary classes.

The use of computers and internet technologies to facilitate learning is generally referred to as e-learning. There are two approaches to e-learning: Self-paced and Instructor-led or facilitated. Both the approaches use e-content which can be broadly classified as simple learning resources, interactive e-lessons, electronic simulations and job aids. ${ }^{25}$ Each interactive e-lesson, henceforth called e-module, is basically an interactive presentation, developed for this study with the aid of H5P- an open source technology to create HTML5 content without much technical expertise. For designing and developing the e-modules, ASSURE 
model of instructional design was adopted. ASSURE is an acronym, as represented in Figure 1.

\begin{tabular}{|l|l|}
\hline & - Analyse Learner \\
\hline & - State Objectives \\
\hline O Select Methods, Media and Materials \\
\hline E & - Utilize Media and Materials \\
\hline
\end{tabular}

Figure I.Representation of the steps mentioned for ASSURE model by Heinich $\mathbf{R}$ et al. $^{26}$

Each e-module consists of a linear sequence of screens with text, graphics, animations, and interactivity in the form of true/false, multiple-choice, drag and dropbox, etc. The e-modules also contain reading links and links for audio-video and links for additional information on few selected topics. The images, graphics, and videos used in the content were taken from Open Educational Resources.

The e-modules were designed and developed under 4 subheadings: Adolescence and Puberty, Role of Hormones and Development of Secondary Sexual Characteristics, Human Reproductive system, and Reproductive Health. Each interactive e-module can be completed in around 30 minutes and consists of an introduction, learning objectives, content, interactive activities, and recapitulation or summary. On parallel lines, lesson plans were prepared with the same content as the e-modules. Both the e-modules as well as lesson plans were validated by experts. Content of the e-modules has been carefully picked up, keeping in mind the curriculum prescribed by the Central Board of Secondary Education and NCERT science text books for classes sixth, seventh and eighth. ${ }^{27-29}$ After two individual tryouts and a group trial with 34 students, the final versions of e-modules were ready. Also, during this phase, the pretest tool 'Questionnaire for Adolescents' and post-test tool- 'Post Intervention Questionnaire for Adolescents' were developed and validated through a pilot. Both the tools consist of 29 multiple choice items each. The reliability coefficient, KR-20 for pre-and post-test tool, was found to be 0.78 and 0.79 respectively.

\section{Phase II (Experimental Phase)}

For the second phase of the study, which required ascertaining the effectiveness of the e-modules developed in the previous stage, quasi-experimental research with non-equivalent control group design was adopted. The study was conducted in Sonipat district of Haryana, with a population of around 15 lakhs, a neighbouring town of Delhi which falls under NCR. The population for the present study comprised all the students enrolled and studying in Upper Primary Classes (six to eight) in Haryana. The sampling frame includes students of class eight from co-educational, English medium CBSE affiliated schools of Sonipat district. A list of CBSE-affiliated schools in Sonipat district was drawn and cross-checked. Out of 122 listed schools, 90 secondary and higher secondary schools were affiliated to CBSE and had the facility of computers as per UDISE data available for the previous session (2018-19). ${ }^{30}$ From the list, randomly 22 schools were selected for the study. The researcher then sought permission from the schools. Ten schools met the necessary technological requirement and gave permission for the conduct of the study. The schools were coded and assigned into two groups, with five schools each. The treatment was randomly assigned to one group, the experimental group ( $\mathrm{N}=155)$, in which subjects were taught through e-modules. Subjects in the control group $(\mathrm{N}=154)$ were taught through the conventional method (lecture cum demonstration).

A pre-test was administered in both groups by the investigator. To avoid bias, both the groups were taught adolescent reproductive health by the investigator. The experimental group was taught through e-modules and the control group through the conventional method using charts and flashcards. Each session was of 40 minutes duration spread over six days. A post-test tool was administered to ascertain the enhancement in the awareness level post sessions in both groups. The study was executed and data collected over three months from Dec.19 to Feb.20. The data set obtained was cleaned and entered into MS Excel and IBM SPSS version 22 to draw a comparison between the experimental $(n=155)$ comprising of 83 males and 72 females and control group ( $n=154)$ comprising of 79 males and 75 females. The average age of subjects was 12.97 years.

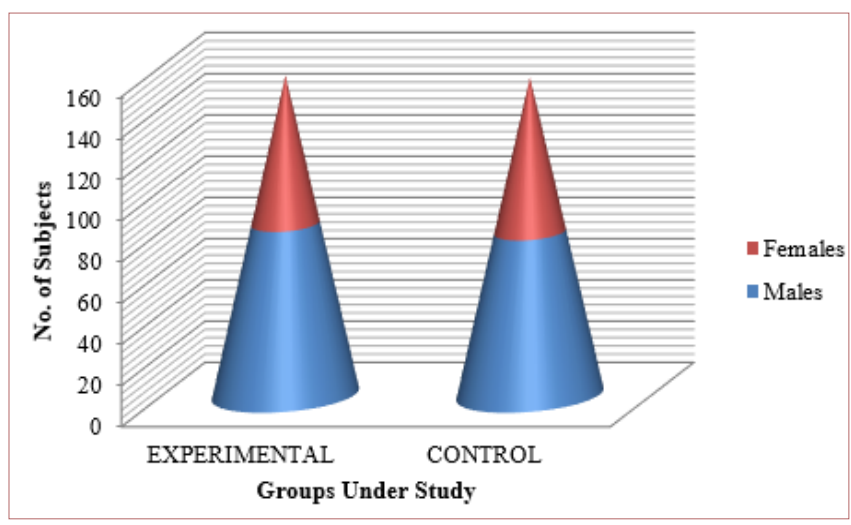

Figure 2.Gender wise representation in Experimental and Control Group 


\section{Result}

Before proceeding with the analysis, the equivalence of groups was established based on pre-test scores. $F$ test results ( $F=0.916$, d.f. $=154,153, p>0.01)$ revealed there is no significant difference between the variances of the two groups. Results of t-test for equal variance $(t=-0.4613$, d.f. $=307, p>0.01$ ) reveal no significant difference between the mean of Pre-test scores (PTS) of both the Experimental Group and Control Group. Hence the two groups were comparable.

In order to ascertain the effectiveness of the intervention, the performance of subjects in both the groups was compared on the basis of their scores obtained in the post-test (PSTS) by applying a t-test for unequal variance. Result for the same is represented in Table 2.

Table I.Mean and variance comparison of PTS and PSTS of experimental $(n=I 55)$ and control group $(n=I 54)$

\begin{tabular}{|c|c|c|c|c|}
\hline & \multicolumn{2}{|c|}{ Pretest scores } & \multicolumn{2}{c|}{ Posttest scores } \\
\cline { 2 - 5 } & Mean & Variance & Mean & Variance \\
\hline $\begin{array}{c}\text { Experimental } \\
\text { group }\end{array}$ & 13.61 & 16.53 & 20.50 & 11.54 \\
\hline Control group & 13.83 & 18.06 & 15.72 & 16.23 \\
\hline
\end{tabular}

Table 2.Comparing the mean of PSTS of experimental $(n=155)$ and control group $(n=154)$

\begin{tabular}{|c|c|c|c|c|}
\hline $\begin{array}{c}\text { Post Test Scores } \\
\text { (PSTS) }\end{array}$ & Mean & S.D & t value & $\begin{array}{c}\text { Effect } \\
\text { Size }\end{array}$ \\
\hline $\begin{array}{c}\text { Experimental } \\
\text { group }\end{array}$ & 20.50 & 3.40 & 11.26 & 1.29 \\
\cline { 1 - 3 } Control group & 15.72 & 4.03 & & \\
\hline
\end{tabular}

d. f. 297, $p<0.001$.

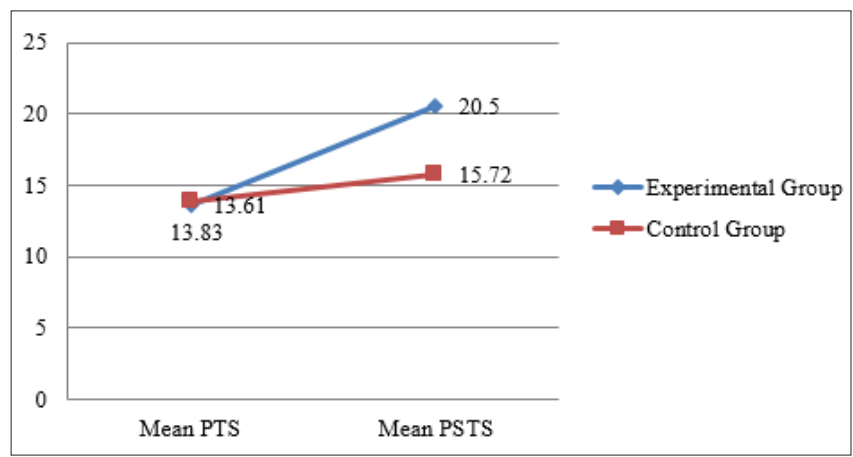

Figure 3.Comparison of means of the experimental and control group on PTS and PSTS

Table 2 indicates that the difference in the means (4.77) of Post Test Scores (PSTS) of the experimental group and the control group is statistically significant ( $t=11.26$, d.f.297, $p$ $<0.001$ ). The experimental group had a higher mean than the control group, which is attributed to the intervention used in the experimental group. The effect size (Cohen's d) calculated is 1.28 , which is $>.80$, so it is inferred that the magnitude of intervention was large.

\section{Discussion}

The pre-test scores of both the groups were low, thus indicating a lack of awareness regarding reproductive health. However, post-intervention, gain in scores on post-test in the experimental group is attributed to the e-modules as indicated by data analysis. The little gain observed in the scores of the control group indicates inefficient discourse of reproductive health matters in the classroom. Therefore, even when the conventional method was used to address reproductive health in the control group, it led to better awareness among subjects as reflected by the scores on the post-test.

Studies have reported that integration of H5P technology has enhanced learning outcomes, improved learning efficiencies, and reduced the cost of practical sessions. ${ }^{31,32}$ The e-modules developed to address Adolescent Reproductive Health have been found to be effective in creating awareness among students of upper primary classes in Haryana. The results are in conjunction with studies of Lavanya S, ${ }^{33}$ Phulambrikar RM, ${ }^{34}$ Calabrese $S,{ }^{24}$ Roberto AJ et al. ${ }^{20}$ and Singh $S$ et al., ${ }^{35}$ who reported the effectiveness of digital interventions to address reproductive and sexual health in classrooms. However, the findings of the study are antagonistic to the studies by Calise TV et al. ${ }^{36}$ and Gustina $\mathrm{E} \&$ Wibowo $\mathrm{M}^{37}$ who reported no change in knowledge regarding reproductive health post-intervention.

The limitation of this study is that the study was conducted on subjects from English medium CBSE schools of Sonipat district only. Also a few selected topics addressing adolescent reproductive health were taken for designing and development of the e-modules through H5P. Further research can be conducted on similar lines in other school settings, among varied population subset, using different software or authoring tool and on different subject matter.

\section{Conclusion}

The use of digital media in education has helped us evolve as facilitators. H5P is one such user friendly tool that helps us create digital content with our basic computer knowledge without much technical knowledge and expertise. Integrating technology to address sensitive issues like reproductive health in a culturally conservative society is a boon. Technology has given us a promising solution to solve the problem of lack of trained persons. Integration of technology in teaching learning context can be used to reach out and connect to the digital natives quickly and easily. E-content on sensitive topics can serve as a nonhuman intervention that helps reduce shyness among students and allow them to acquire age-appropriate and scientifically correct knowledge. In possession of accurate 
knowledge, the adolescents will be empowered to make mature decisions, maintain overall health, and remove shackles surrounding the taboo subject 'sex'.

\section{Sources of Funding: None \\ Conflict of Interest: None}

\section{References}

1. Prensky M. Digital Natives, Digital Immigrants Part 1. On the Horizon 2001; 9(5): 1-6.

2. Chandra-Mouli V, Plesons M, Barua A et al. Adolescent sexual and reproductive health and rights: a stocktaking and call-to-action on the 25th anniversary of the international conference on population and development. Sexual and Reproductive Health Matters 2019; 27(1): 336-9.

3. Patton GC, Sawyer SM, Santelli JS et al. Our future: a Lancet commission on adolescent health and wellbeing. The Lancet 2016; 387(10036): 2423-78.

4. Kingsley KV, Boone R. Effects of multimedia software on achievement of middle school students in an American History Class. Journal of Research on Technology in Education 2008; 41(2): 203-221.

5. Ercan 0 . The effects of multimedia learning material on students' academic achievement and attitudes towards science courses. Journal of Baltic Science Education 2014; 13(5): 608-621.

6. George J. Effect of multimedia approach on knowledge and skills in and attitude of students towards science at upper primary level (Doctoral Thesis). 2015.

7. Aljaser AM. The Effectiveness of e-learning environment in developing academic achievement and the attitude to learn English among primary students. Turkish Online Journal of Distance Education 2019. 176-194.

8. Nair P, Grover V, Kannan A. Awareness and practices of menstruation and pubertal changes amongst unmarried female adolescents in a rural area of East Delhi. Indian Journal of Community Medicine 2007; 32(2): 156.

9. Ray S, Ghosh T, Mondal PC et al. Knowledge and information on psychological, physiological and gynecological problems among adolescent school girls of Eastern India. Ethiop J Health Sci 2011; 21(3): 183-189.

10. Das B, Desai G. KAP study of reproductive health and sexually transmitted diseases among high school girls of Vadodara city. International Journal of Medical Science and Public Health 2016; 5(3): 412.

11. Srivastava U, Singh KK. Exploring knowledge and perceptions of school adolescents regarding pubertal changes and reproductive health. Indian Journal of Youth and Adolescent Health 2017; 4(1): 26-35.

12. Chandra-Mouli V, Patel, SV. Mapping the knowledge and understanding of menarche, menstrual hygiene and menstrual health among adolescent girls in low- and middle-income countries. Reproductive Health 2017; 14(1): 30-46.

13. Ramadugu S, Srivastava K, Prakash J, et al. Understanding sexuality among Indian urban school adolescents. Industrial Psychiatry Journal 2012; 20(1): 49.

14. Patel V, Andrew G. Gender, sexual abuse and risk behaviours in adolescents: A cross-sectional survey in schools in Goa. The National Medical Journal of India 2001; 14(5): 263-267.

15. Mehra S, Daral S, Sharma S. Investing in our adolescents: assertions of the 11th world congress on adolescent health. Journal of Adolescent Health 2018; 63(1): 9-11.

16. UN Population Fund (UNFPA). Motherhood in childhood: Facing the challenge of adolescent pregnancy. 2013.

17. Adolescence: a second chance to tackle inequities. The Lancet 2013; 382(9904): 1535.

18. Barak A, Fisher WA. Experience with an Internet-based, theoretically grounded educational resource for the promotion of sexual and reproductive health. Sexual and Relationship Therapy 2003; 18(3): 293-308.

19. Cousineau TM, Franko DL, Green TC et al. Body morph: feasibility testing of an interactive CD-ROM to teach young adolescents about puberty. Journal of Youth and Adolescence 2006; 35(6): 1015-1021.

20. Roberto AJ, Zimmerman RS, Carlyle KE et al. A computerbased approach to preventing pregnancy, STD, and HIV in rural adolescents. Journal of Health Communication 2007; 12(1): 53-76.

21. Bailey JV, Murray E, Rait G et al. Interactive computerbased interventions for sexual health promotion. Cochrane Database of Systematic Reviews 2010; 9: 1-81.

22. Sancheti PV, Mangulikar SK, Mulaje SM. Interventional study to assess knowledge and attitude of school going adolescents about reproductive health. International Journal of Interdisciplinary and Multidisciplinary Studies 2014; 2(2): 96-99.

23. Brayboy LM, Mezoian T, Sepolen A, et al. Girl talk: a smartphone application to teach sexual health education to adolescent girls. Journal of Pediatric and Adolescent Gynecology 2016; 29(2): 161.

24. Calabrese $S$. Adolescent sexual reproductive health course: a mixed media intervention and quality improvement project in a school-based setting. Doctor of Nursing Practice (DNP) Projects, 2019.

25. Ghirardini B. E-learning Methodologies. Food and Agriculture Organization of the United Nations. 2011.

26. Heinich R, Molenda M, Russel JD et al. Instructional Media and Technology for Learning (7th ed.). Pearson Education, 2002. Available from: http://hdl.handle. net/123456789/274.

27. NCERT. Science Textbook for Class - 6. NCERT. 2007.

28. NCERT. Science Textbook for Class - 7. NCERT. 2007. 
29. NCERT. Science Textbook for Class - 8. NCERT. 2007.

30. UDISE+. Available from: https://udiseplus.gov.in/.

31. Ibrahim FI, Hassan N, Fun TLV. Enhancing students' experience with H5P learning activities developed according to triple e framework (engage, enhance and extend). In Chen CJ (Ed.), Proceedings of the International University Carnival on E-Learning 2019; pp. 26-27.

32. Handayani AP, Singaram M, Har LS. Use of H5P interactive video to support action learning of plant tissue culture technique. In Chen CJ (Ed.), Proceedings of the International University Carnival on E-Learning 2019; 35-36.

33. Lavanya S. F - 07: Effectiveness of ICT based teaching programme on knowledge and attitude regarding pubertal health among girls of pre pubertal age group of 9-14 years in selected schools at Puducherry. Annals of SBV 2018; 7(1): 94.

34. Phulambrikar RM, Kharde AL, Mahavarakar VN et al. Effectiveness of interventional reproductive and sexual health education among school going adolescent girls in rural area. Indian Journal of Community Medicine 2019; 44(4): 378-82.

35. Singh S, Kumar R, Singh SK. Effectiveness of structured teaching programme regarding reproductive health on knowledge among adolescent girls in selected school of rural area. International Journal of Community Medicine and Public Health 2021; 8(2): 649.

36. Calise TV, Chow W, Doré KF et al. Healthy futures program and adolescent sexual behaviors in 3 Massachusetts Cities: a randomized controlled trial. American Journal of Public Health 2016; 106(S1): S1039.

37. Gustina E, Wibowo M. Improving knowledge and changing health attitude among teenagers through digital media flipbook. Journal of Educational Science and Technology 2020; 6(1): 15-22. 